\title{
Analysis of the influence of zero potential live operation on protection
}

\author{
Yang Qi ${ }^{1,2}$, Wang Zhenyu ${ }^{1,2^{*}}$, Zhu Liang ${ }^{1,2}, \mathrm{Xu} \mathrm{Li}^{1,2}$, Zhen Chaohui ${ }^{1,2}$ \\ ${ }^{1}$ Hunan transmission Maintenance Company,Changsha 410100, China \\ ${ }^{2}$ Live Inspection and Intelligent Operation Technology State Grid Corporation Laboratory, Changsha 410100, China.
}

\begin{abstract}
In the case of live working in the distribution network, a live method of live working that satisfies the requirements for personal safety and power supply reliability needs to be studied, because of the serious safety accidents caused by misuse and weak safety awareness. Based on the analysis of singlephase buck symmetrical operation characteristics, a new method of zero-potential live working of distribution network based on injection current is proposed. By injecting current into the neutral point, the zero-sequence voltage is regulated so that the neutral point voltage is equal to the value of the operating phase line voltage drop minus the operating phase power supply voltage, ensuring that the operating point voltage is zero. Based on the principle of current fast-break protection and time-limited overcurrent protection, it is analyzed that the zero-potential uninterruptible operation method of the distribution network will not affect the distribution network protection. Finally, the system model is established based on the MATLAB. The simulation verifies the feasibility of the method by the operating phase voltage curve and the correctness of the protection impact analysis by comparing the non-working phase current curve with the protection setting.
\end{abstract}

\section{Introduction}

With the rapid development of China's power grid and the continuous improvement of power supply reliability requirements[1], the research and standardization work of the live working technology has become a new development and breakthrough[2]. If the fault cannot be removed within a short time, it would affect the reliability of the power supply and the quality of the power supply[3-4]. Therefore, live working as an important means to improve power supply reliability and service quality has received increasing attention. It was of great practical significance for the study of the methods and their impact on distribution network protection[5-6].

In recent years, the research on live working in the distribution network has been rapidly developed in order to meet the diversification of the distribution network operation mode and grid structure. In the current study, there were two main ways of not stopping power:(1) Working directly on live lines or equipment. Reference [7] divided live working into ground potential operation method, intermediate potential operation method, and equipotential operation method; The trial range of live working methods has been studied in [8]; In [9], the safety spacing and operation mode of live working were studied, and the actual operation simulation test of the live working of the insulated bucket car was carried out. (2) Continuous power supply to users by means of bypass or mobile power. Reference [10] proved that the charging operation under bypass conditions is safe; Reference [11] introduced the method of implementing protective grounding for bypass flexible cable in integrated unpowered operation of $10 \mathrm{kV}$ distribution network; Three mobile power operation methods for mobile power generation vehicles, load transfer vehicles and EPS emergency power supply vehicles were introduced in [12]. The prior art has certain security risks, so it satisfied the requirements for personal safety and power supply reliability, and neglects the impact of nonoperation phase protection after taking measures[13].

In view of this, a new method based on injection current for zero-potential live working of distribution network is proposed. The zero-sequence current injection method was studied, and the zero-potential uninterrupted power removal method and implementation strategy were proposed, based on the zero-potential theory and technology of the operating point. The impact of adopting this method on distribution network protection is analyzed. Finally, the simulation software MATLAB is used to verify the feasibility of the proposed method and the correctness of the impact analysis.

\section{The Method of Zero-potential Live working of Distribution Network}

To regulate the voltage of any working phase, a power supply device or a power electronic device can be 
used to inject current $\left(\dot{I}_{i}\right)$ into the neutral point. Taking the $\mathrm{C}$ phase as an example, the vector diagram is used for analysis. The current is injected into the neutral point through the grounding transformer, and the zerosequence voltage will appear in each phase. It will cause the neutral point to ground voltage $\left(\dot{U}_{\mathrm{N}}\right)$ to shift. The power supply and load are not affected by the phasedown of the C-phase. Therefore, the non-effective grounding distribution system has the natural advantage of maintaining the line voltage symmetric operation when single-phase step-down, and the single-phase stepdown symmetrical operation is feasible.

After the C-phase regulation voltage is reduced, the other phase-phase voltages will increase, which may affect the safety of the distribution network.

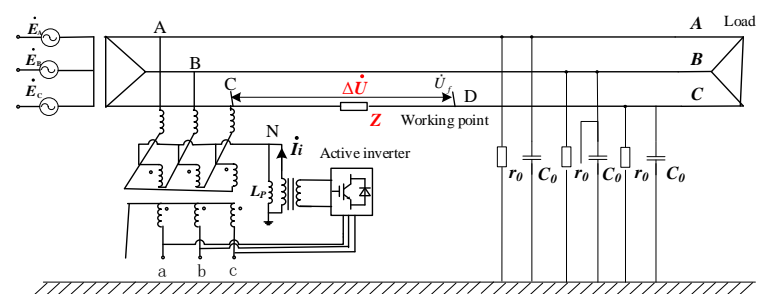

Figure 1. Working point zero potential control schematic

In Fig. 1, the C-phase line needs to be energized. Assume that the operating point voltage is $\dot{U}_{\mathrm{f}}$, the neutral point voltage is $\dot{U}_{\mathrm{N}}$, the line unit impedance is $\mathrm{z}$, the voltage drop between the power bus and the operating point is $\Delta \dot{U}$, and the three-phase power supply voltage is respectively $\dot{E}_{A} 、 \dot{E}_{B} 、 \dot{E}_{C}$.

The concentrated series impedance can be used as the equivalent impedance of the line, due to the lower voltage level and lower capacitance current in the distribution network of $35 \mathrm{kV}$ and below. With reference to the precise positioning technique proposed in [14], the distance between the operating point and the power bus( $l$ ) can be obtained. When the operating phase current is $\dot{I}_{C}$, the voltage drop between the power bus and the operating point $(\Delta \dot{U})$ can be calculated as shown in equation (1).

$$
\Delta \dot{U}=z l_{C} \dot{I}
$$

Analysis of the neutral point, equation (2) can be obtained.

$$
\dot{I}_{i}=\left(\dot{E}_{A}+\dot{U}_{N}\right) Y_{0}+\left(\dot{E}_{B}+\dot{U}_{N}\right) Y_{0}+\left(\dot{E}_{C}+\dot{U}_{N}-\Delta \dot{U}\right) Y_{0}+\dot{U}_{N} Y_{L}
$$

Where $\dot{I}_{i}$ is the current injected into the neutral point, $Y_{0}$ is the admittance to the ground during normal operation of the grid, and $Y_{L}$ is the admittance of the arc suppression coil to ground.

Analysis of the C-phase circuit, equation (3) can be obtained.

$$
\dot{U}_{N}=\dot{U}_{f}-\dot{E}_{C}+\Delta \dot{U}
$$

Assuming $\dot{U}_{f}=0$, equation (4) can be obtained. Therefore, if and only if the neutral point voltage is equal to the value of the operating phase line voltage drop minus the operating phase power supply voltage, the operating point voltage is guaranteed to be zero.

$$
\dot{U}_{N}=-\dot{E}_{C}+\Delta \dot{U}
$$

Considering the formula (1)-(4) comprehensively, the expression of the injected current required by the zeropotential uninterruptible operation method of the distribution network can be calculated.

$$
\dot{I}_{i}=\left(-\dot{E}_{C}+\dot{I}_{C} z l\right)\left(3 Y_{0}+Y_{L}\right)-\dot{I}_{C} z l Y_{0}
$$

\section{The Effect of Non-working Phase Current Rise on Protection}

Current fast-break protection and time-limited overcurrent protection are generally used in distribution network. However, the above method will bring about the phenomenon that the non-working phase current rises. Therefore, whether it affects the distribution network protection needs to be analyzed.

Current quick-break protection is set according to the short-circuit current of the protected equipment. The operating current can be adjusted according to equation (6).

$$
I_{\text {set }}=K_{r e l} \cdot I_{C \cdot \max }
$$

Where $I_{\text {set }}$ is current of setting; $K_{r e l}$ is the reliability coefficient $\left(K_{r e l}=1.2\right.$ ); $I_{C \text {. max }}$ is the maximum shortcircuit current possible when the line ends are shortcircuited.

In the distribution network, the maximum shortcircuit current at the end of the line is the following relationship with the normal load current.

$$
I_{C . \max } \geq \sqrt{3} * I_{C . l}
$$

After the injection current reaches the zero potential of the working phase, the non-working phase current will rise to $\sqrt{3}$ times the normal load current, as shown in equation (8).

$$
I_{A}=\sqrt{3} * I_{C . l}
$$

Considering equations (6)-(8), $I_{\text {set }}$ is available.

$$
I_{\text {set }} \geq 1.2 * \sqrt{3} * I_{C . l}>I_{A}
$$

It can be seen from equation (9) that the setting value is much larger than the non-working phase current. Therefore, the current quick-break protection is not affected, after the injection current reaches the zero potential of the working phase according to the setting principle of the current quick-break protection.

In order to achieve the selectivity of the time-limited overcurrent protection, the action time of each protection is generally set according to the step principle. The 
operating current can be adjusted according to equation (10).

$$
I_{s e t}^{\prime}=\frac{K_{r e l}^{\prime} \cdot K_{s s}}{K_{r e}} I_{L \cdot \max }
$$

Where $I_{s e t}^{\prime}$ is current of setting; $K_{r e l}^{\prime}$ is the reliability coefficient $\left(K_{r e l}^{\prime}=1.2\right) . K_{s s}$ is the self-starting coefficient $\left(K_{s s}=2\right) ; K_{r e}$ is the return of the current relay $\left(K_{s s}=0.95\right) ; I_{L \cdot \max }$ is the maximum load current during normal operation.

Considering equations (8) and (10), equations (11) is available.

$$
I_{\text {set }}^{\prime}=2.52 I_{L \cdot \max }>I_{A}
$$

It can be seen from equation (11) that the setting value is much larger than the non-working phase current. Therefore, the time-limited overcurrent protection is not affected, after the injection current reaches the zero potential of the working phase according to the setting principle of the time-limited overcurrent protection.

In summary, the above method will not cause misoperation of the distribution network protection.

\section{$4 \quad$ Zero Operation Process \\ Potential Non-Blackout Method Implementation}

The implementation process of the zero point potential non-blackout operation method at the operation point is shown in Figure 1. When the work is performed at the working point, the voltage of the phase is adjusted so that the operating point voltage is zero, and since the operating space of the side phase is large, the safety of the working point personnel can be ensured.

For the phase-to-phase voltage, the amplitude and phase of the three-phase line voltage are changed due to the displacement of the neutral point voltage during regulation, and the symmetrical operation can be maintained to achieve the purpose of non-power-off operation.

Since the line voltage between the phases is not raised, no additional protection is required under existing protection measures. The voltage at the working point is zero by the voltage regulation during operation, which ensures personal safety. When phase-to-phase shorting occurs, the short-circuit current is the same as when the voltage is not regulated, and no additional damage is caused to the operator.

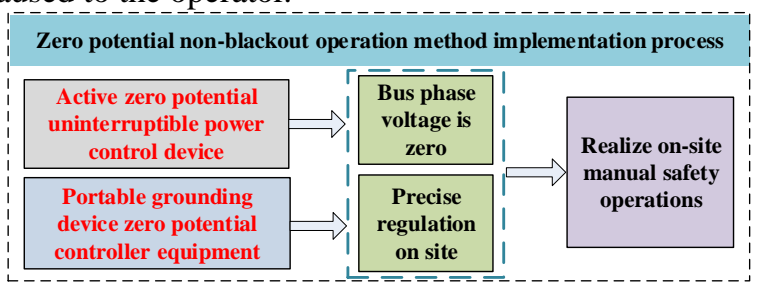

Figure 2. Operation method implementation process.
As shown in Fig. 1, the single-phase step-down operation diagram of the $10 \mathrm{kV}$ distribution network is built in MATLAB. The active inverter device is connected between the neutral point and the earth. It can be equivalent to a controllable current source, and the output current is $\dot{I}_{i}$.

$\dot{E}_{\mathrm{A}} 、 \dot{E}_{\mathrm{B}} 、 \dot{E}_{\mathrm{C}}$ is the grid power supply voltage; $r_{\mathrm{A}} 、 r_{\mathrm{B}} 、 r_{\mathrm{C}}$ are the relative resistance of the grid three, $C_{\mathrm{A}} 、 C_{\mathrm{B}} 、 C_{\mathrm{C}}$ are the relative capacitance of the grid three; The neutral point $\mathrm{N}$ is grounded by the arc suppression coil, and $\mathrm{L}$ is the arc suppression coil inductance. The ground leakage resistance is $44 k \Omega$; The ground capacitance is $14.9 \mu \mathrm{F}$; The arc suppression coil gear setting is $0.2 \mathrm{H}$.

When the live working is carried out at point $\mathrm{D}$ of phase $\mathrm{C}$, the zero-potential uninterruptible operation method of the distribution network described in the first section is adopted. The neutral point injection current $\left(\dot{I}_{i}=12.36 \angle 65.99 A\right)$ is obtained, substituting the parameters into equation (5).

The current is injected into the system at 1 second, and the phase change curve of the operating phase $\mathrm{C}$ is shown in Fig. 3. It can be seen from the figure that the C-phase voltage becomes 0 after the current injection, which verifies the feasibility of the zero-potential uninterrupted operation method of the proposed distribution network.

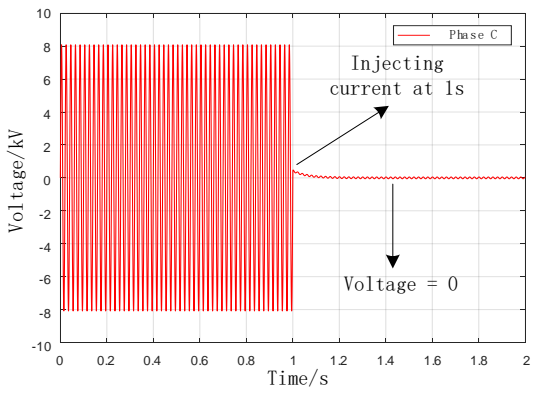

Figure 3. Phase $\mathrm{C}$ voltage change

Fig. 4 is a graph showing the non-working phase current. It can be seen that the two non-working phase currents are increased to $\sqrt{3}$ times the load current when 0.2 s current is injected.

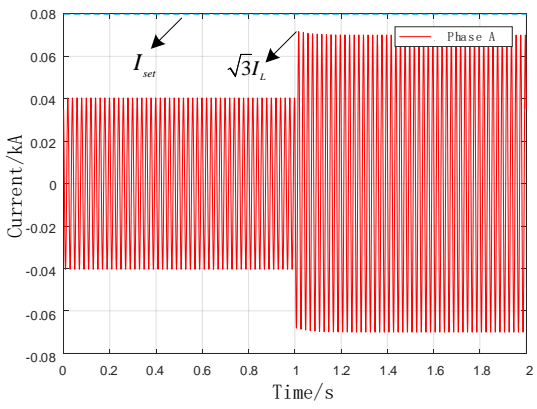

(a) Phase A

\section{Verification of Simulation}




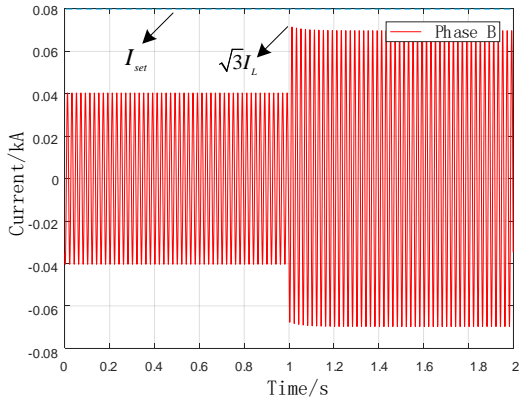

(b) Phase B

Figure 4. Non-working phase current change

The distribution network generally adopts current fast-break protection and time-limited over-current protection. The system parameters are substituted into equations (6) and (10), and the current quick-break protection and the time-limit overcurrent protection current setting value can be obtained.

$$
\left\{\begin{array}{l}
I_{\text {set }}=82.8 \mathrm{~A} \\
I_{\text {set }}^{\prime}=100.8 \mathrm{~A}
\end{array}\right.
$$

It can be seen from Fig. 4 that the non-operation phase current does not exceed the current quick-break protection and the time-limit overcurrent protection setting value. Therefore, the zero-potential non-currentoff operation method of the above-mentioned distribution network will not affect the distribution network protection.

\section{Conclusion}

In the distribution network, serious accidents will occur due to misuse and weak safety awareness during live working. In order to improve the reliability of power supply and personal safety, a new method based on injection current for zero-potential uninterrupted operation of distribution network is proposed. Here are some conclusions as follows:

1. By injecting current into the neutral point, the zero-sequence voltage is adjusted so that the neutral point voltage is equal to the value of the operating phase line voltage drop minus the operating phase power supply voltage, ensuring that the operating point voltage is zero;

2. Adopting the zero-potential uninterrupted operation method of the distribution network will bring the current increase phenomenon to the non-working phase, which will not affect the current quick-break protection and the time-limited overcurrent protection;

3. The simulation verifies the feasibility of the method by the operating phase voltage curve and the correctness of the protection impact analysis by comparing the non-working phase current curve with the protection setting by MATLAB.

\section{References}

1. LIU Jian, LIN Tao, ZHAO Jianghe, et al. Specific planning of distribution automation systems based on the requirement of service reliability[J], Power System Protection and Control, 2014(11): 52-60.

2. Nasibov F, Yorukoglu S, Gul O, et al. A feasibility study of live working in Turkish electricity distribution system[C]// International Conference on Live Maintenance. 2017.

3. Ch Venkaiah, Kokkula Divyasree, Seshu Kumar P, A coordinated optimization of dg capacity, location with optimal use of distribution network using GA, International Journal of Electrical and Electronic Engineering \& Telecommunications, Vol. 3, No. 2, pp. 41-49, April 2014.

4. WU Simou, CAI Xiuwen, WANG Hailiang, et al. Planning method and its application of distribution network based on power supply reliability[J], Proceeding of the CSU-EPSA, 2014, 26(6): 70-75.

5. Stepanov A M, Fakhrutdinova A N, Mamedov D V, et al. Phase goniometer calibration at observation of meteor tracks[J]. Kazan. Gos. Univ. Uchen. Zap. Ser. Fiz.-Mat. Nauki, 2009, 3(3):31-40.

6. Kishore P A K, Padma Priya K, Low power clock distribution network using clock paired shared flip flop, International Journal of Electrical and Electronic Engineering \& Telecommunications, Vol. 5, No. 4, pp. 18-27, October 2016.

7. LI Tianyou. A review of the development of nonservice interruption working technology in distribution network[J], DISTRIBUTION \& UTILIZATION, 2015, 32(05): 6-10+21.

8. Huang Z L, Zhang Q S, Liu C X, et al. The Application Discussion of Virtual Reality Technology in Power Distribution Network Live Working Training[J]. Applied Mechanics \& Materials, 2013, 278-280:2152-2155.

9. DENG Heming, CAI Wei, YU Xin, et al. Methods and safety protection of live working on $66 \mathrm{kV}$ transmission lines by aerial device with insulating boom[J], High Voltage Engineering, 2015, 41(9): 3091-3096.

10. WANG Jianming, SU Ziming,WANGJian-ming, et al. EMTP simulation calculation of bypass transformer operation in $10 \mathrm{kV}$ distribution network[J], East China Electric Power, 2013, 41(6): 1241-1245.

11. YANG Xiaoxiang, MAO Yanping. Protective earthing of the bypass flexible cable for non-lackout working on $10 \mathrm{kV}$ distribution network[J], East China Electric Power, 2013(08): 141-145.

12. NI Zhijian, WANG Yang, LI Xiaolan, et al. Comparison on several finds of distribution network without power outage[J], NORTHEAST ELECTRIC POWER TECHNOLOGY, 2016(9): 5355.

13. Qiu Maosheng. Research of live working on $10 \mathrm{kV}$ distribution lines in Gansu area cooperation anechanism[D], School of Electric\&Electronic Engineering, 2014. 
14. CHANG Zhongxue, SONG Guobing, HUANG Wei, et al. Phase voltage and current fault components based fault segment location method under single- phase earth fault in distribution network[J], Power System Technology, 2017(7): 2363-2369. 